\title{
Kinetics of Vitamin A Degradation and Oxidation of Palm Oil Fortified with Retinyl Palmitate and $\beta$-Carotene from Red Palm Oil
}

\author{
Krisna Margaretta Malau, ${ }^{1,2}$, Nuri Andarwulan', Drajat Martianto1, \\ Desty Gitapratiwi ${ }^{1}$, Ayu Cahyaning Wulan ${ }^{1}$, Dwi Fitriani ${ }^{1}$, Purwiyatno Hariyadi ${ }^{*}$ \\ ${ }^{1}$ IPB University, Bogor 16680, Indonesia. \\ ${ }^{2}$ Manokwari Agricultural Development Polytechnic, Manokwari 98312, Indonesia.
}

\begin{abstract}
Retinyl palmitate and $\beta$-carotene from red palm oil (RPO- $\beta$-carotene) can be used as sources to fortify vegetable oil. The present study tested three types of bulk palm cooking oil with a peroxide value (PV) of $0, \pm 4$ and $\pm 8 \mathrm{mEq} \mathrm{O}_{2} \mathrm{~kg}^{-1}$ which each was fortified with retinyl palmitate or RPO- $\beta$-carotene alone and combination of both fortificants. The stability of the fortificants in oil samples during storage was investigated. A kinetic analysis of oxidation reaction in fortified palm cooking oil stored in tightly closed amber vials in the dark at different temperatures $(60 \pm 5$, $75 \pm 5$ and $90 \pm 5^{\circ} \mathrm{C}$ ) was conducted and then PV, vitamin A concentration and their change rate of reaction in the oils were measured. It reveals that initial PV and mixture of retinyl palmitate and RPO- $\beta$-carotene in fortified oil affected the oil stability. Higher initial PV of oil increased the reaction rate constant of peroxide formation and degradation of vitamin A activity during storage. Oxidation reactions of oil samples fortified with the mixtures of retinyl palmitate and RPO- $\beta$-carotene was faster than that fortified with retinyl palmitate or RPO- $\beta$-carotene only. Our research suggests that applying single fortificant of retinyl palmitate or RPO- $\beta$-carotene in oil is more stable than that fortified with combination of both fortificants.
\end{abstract}

Keywords: combination fortificants, kinetics degradation, palm cooking oil, peroxide value, red palm oil, retinyl palmitate

\section{INTRODUCTION}

Vitamin A deficiency still becomes a serious public health problem in many developing countries due to insufficient dietary intake of vitamin A-rich foods and poor availability of this micronutrient (Akhtar et al. 2013). A deficiency in vitamin A may lead to blindness, disturbance in growth and susceptibility of severe infections, and increase mortality risk in childhood and lactating women (WHO \& FAO 2006). Nutritional surveys from various countries consistently report $\beta$-carotene intake to be essential to meet vitamin A requirements (Grune et al. 2010). A series of strategies has been used to improve vitamin A status of populations,

\footnotetext{
${ }^{*}$ Corresponding author:

Department of Food Science and Technology, Faculty of Agricultural Engineering and Technology, IPB University, Bogor 16680, Indonesia.

Email: phariyadi@apps.ipb.ac.id.
} 
among other through dietary diversification, vitamin A supplementation and fortification (Bruins et al. 2013). Fortification of a staple food or condiment with micronutrient is considered as an appropriate, logical and recommended intervention program to be applied in developing countries with large populations (Chadare et al. 2019). Fortifying vegetable oil on a large scale in Malaysia and Indonesia can reach millions of people globally, including children less than 5 years old (Laillou et al. 2013). The initiation of food-based interventions involving its use in developing countries with an endemic vitamin $A$ deficiency problem appears to be a logical choice (Benadé 2003). Indonesia has mandatory for palm cooking oil to be fortified with vitamin $A$ to a level of at least $45 \mathrm{IUg}^{-1}$ (Ministry of Industry Regulation Number 87/M-IND/PER/12/2013 and Indonesian National Standard 7709/2019). Retinyl palmitate is the most common fortificant used for decades in food supplementation and fortification due to its good stability in fortified cooking oils during storage in the dark, and when it was used for frying (WHO \& FAO 2006). Retinyl palmitate in fried products and its stability indicate that oil fortified with retinyl palmitate can be a useful vehicle for delivery of vitamin A activity (Simonne \& Eitenmiller 1998). Naturally occurring $\beta$-carotene from red palm oil (RPO- $\beta$-carotene) is recently re-raised and highlighted as an alternative fortificant of vitamin $A$ due to its high provitamin A activity and bioavailability (Souganidis et al. 2013). In countries with a major palm oil production like Indonesia, the use of RPO- $\beta$-carotene as a source to fortify palm cooking oil is a cost-effective and easily implementable option of the intervention strategy (West 2008). However, its stability in cooking oil is still questioned whether it is as effective as retinyl palmitate for fortification. A review by Souganidis et al. (2013) predicted that RPO intervention can be efficacious in preventing vitamin A deficiency but it is suggested to use retinyl palmitate rather than RPO- $\beta$-carotene in palm oil to ensure that there is adequate vitamin A content. Recent studies reported that the stability of vitamin A added in vegetable oils was determined by the initial oxidation level of peroxide value (PV); in which it is recommended that initial $P V$ of vegetable oil must be kept as low as possible ( $\leq 2$ $\mathrm{mEq} \mathrm{O}_{2} \mathrm{~kg}^{-1}$ ) to successfully accomplish objective of vitamin A fortification (Laillou et al. 2012). Therefore, to gain more understanding on the use of retinyl palmitate or RPO- $\beta$-carotene, as well as their combination for cooking oil fortification, we conducted a research to investigate the stability of palm cooking oil added with retinyl palmitate or RPO- $\beta$-carotene as single fortificant, or mixture of both fortificants, simultaneously.

In the present study, an Arrhenius kinetic analysis on degradation of vitamin A activity and oxidation of fortified palm cooking oil in different initial oxidative levels and fortificants used, stored in the dark at different temperatures $(60 \pm 5$, $75 \pm 5$, and $90 \pm 5{ }^{\circ} \mathrm{C}$ ) was conducted, the oxidation level (assessed by PV), vitamin $A$ activity and their rate of change were measured and evaluated.

\section{MATERIALS AND METHODS}

\section{Bulk Palm Cooking Oils and Fortificants}

Three types of bulk palm cooking oils with an initial peroxide value (PV) of $0, \pm 4$ and $\pm 8 \mathrm{mEq} \mathrm{O}_{2} \mathrm{~kg}^{-1}$ were used. Bulk palm cooking oil with a PV of $0 \mathrm{mEq} \mathrm{O} \mathrm{kg}^{-1}$ was obtained from palm oil manufacturer in Jakarta, Indonesia. Bulk palm cooking oils with a PV of \pm 4 and $\pm 8 \mathrm{mEq} \mathrm{O} \mathrm{kg}^{-1}$ were obtained by purchasing locally the bulk palm cooking oil with a PV of $2 \mathrm{mEq}$ $\mathrm{O}_{2} \mathrm{~kg}^{-1}$ and stored at $30-43^{\circ} \mathrm{C}$ for $80 \mathrm{~h}$ and 
$140 \mathrm{~h}$ respectively. The fortificants used were the vitamin A premix, containing retinyl palmitate (1 $700000 \mathrm{IU} \mathrm{g}^{-1}$ ) which was procured through the GAIN (the Global Alliance for Improved Nutrition) premix facility (Geneva, Switzerland) and $\beta$-carotene from red palm (RPO- $\beta$-carotene) oil which was produced by southeast asian food and agricultural science and technology (SEAFAST) Center, IPB University. The palm cooking oils with different initial PVs and fortificants were chemically characterized, i.e. peroxide value, free fatty acids, retinyl palmitate concentration and $\beta$-carotene concentration, before used in the fortification process.

\section{Chemicals and Reagents}

All chemicals and reagents for analysis were purchased from Merck KgaA (Darmstadt, Germany) or J.T Baker (Center Valley, PA, USA). Retinyl acetate used as internal standard for vitamin A determination using HPLC was purchased from Sigma Aldrich (St. Louis, MO, USA).

\section{Fortification Process of Bulk Palm Cooking Oil}

The final concentration of vitamin A in palm cooking oil after fortification was at least $45 \mathrm{IU} \mathrm{g}^{-1}$ oil (1 IU vitamin $A=0.6 \mu \mathrm{g}$ $\beta$-carotene; 1 IU retinol=3 IU $\beta$-carotene) (WHO \& FAO 1967). Each palm cooking oil was added with fortificant(s) with concentration ratio as follows: 45 IU of retinyl palmitate (FOA), 30 IU of retinyl palmitate and $15 \mathrm{IU}$ of RPO- $\beta$-carotene (FOB), $15 \mathrm{IU}$ of retinyl palmitate and 30 IU of RPO- $\beta$-carotene (FOC), $45 \mathrm{IU}$ of RPO- $\beta$-carotene (FOD). Hence, twelve samples of fortified palm cooking oil obtained and were tested.

The diluted retinyl palmitate and/or RPO- $\beta$-carotene was added to, and mixed well with palm cooking oil in agitator mixer with a speed rotation of 180 to $210 \mathrm{rpm}$ for 60 minutes. The mixing process was conducted in the dark at room temperature. The fortified palm cooking oil was then tested the homogeneity of retinyl palmitate and/or RPO- $\beta$-carotene at five points of oil sample. Once homogeny, the fortified oil sample was packed in tightly closed amber vials, stored in the incubators with a three storage temperatures of $60 \pm 5,75 \pm 5$ and $90 \pm 5{ }^{\circ} \mathrm{C}$ and periodically analyzed the peroxide value, free fatty acids, retinyl palmitate and $\beta$-carotene concentration (t1, t2, t3, t4, t5, t6 and t7).

\section{Peroxide Value}

The peroxide value (PV) in oil was determined by AOCS method Cd 8-53. Five $\pm 0.5 \mathrm{~g}$ of sample was weighed, put into $250 \mathrm{~mL}$ Erlenmeyer flask and added 30 $\mathrm{mL}$ of acetic acid-chloroform (2:3) solution (under the hood). The flask was swirled until the sample dissolved and added 0.5 $\mathrm{mL}$ saturated potassium iodide $(\mathrm{KI})$ solution. The solution was allowed to stand with occasional swirling for one minute and then $30 \mathrm{~mL}$ distilled water was added. The solution was titrated by $0.05 \mathrm{~N}$ sodium thiosulfate $\left(\mathrm{Na}_{2} \mathrm{~S}_{2} \mathrm{O}_{3}\right)$ constantly and vigorously shaking. Titrating was continued until the color changes to light yellow. $0.5 \mathrm{~mL}$ (2-3 drops) of $1 \%$ soluble starch indicator which will give a blue color was added. Titrating was continued by shaking the flask vigorously near the endpoint which was a faint blue color to liberate all of the iodine from the chloroform $\left(\mathrm{CHCl}_{3}\right)$ layer. The sodium thiosulfate was drop wised until the blue color just disappears. The peroxide value was calculated using formula as follow:

$$
P V\left(m E q O_{2} / k g\right)=\frac{\text { Volume } \mathrm{Na}_{2} \mathrm{~S}_{2} \mathrm{O}_{3} \times \text { Normality } \mathrm{Na}_{2} \mathrm{~S}_{2} \mathrm{O}_{3} \times 1000}{\text { sample weight }(g)}
$$

\section{Free Fatty Acid}

The percentage of free fatty acid (FFA) in oil sample was determined by the AOCS Ca $5 \mathrm{a}-40$ method. $10 \mathrm{~g}$ of sample 
was weighed into an Erlenmeyer flask, and $50 \mathrm{~mL}$ of $95 \%$ ethanol and $1 \%$ phenolphthalein indicator were added. The mixture solution was heated in water bath for 3 minutes and $2 \mathrm{~mL}$ (2-3 drops) of $1 \%$ phenolphthalein indicator was added. The solution was then titrated with sodium hydroxide solution $(\mathrm{NaOH}) 0.01 \mathrm{~N}$ until the appearance of the first permanent pink color persisted for at least $30 \mathrm{~s}$. The free fatty acid as palmitate (\%) was calculated using following formula:

$$
\text { FFA }(\%)=\frac{\text { Volume NaOH } x \text { Normality } \mathrm{NaOH} \times 25.6}{\text { sample weight }(g)}
$$

\section{$\beta$-Carotene}

Determination of $\beta$-carotene in fortified palm cooking oil sample was according to PORIM Test Method. $10 \mathrm{~g}$ of oil sample was dissolved in hexane in a $25 \mathrm{~mL}$ volumetric flask and diluted to the mark. The solution was then transferred to a 1 $\mathrm{mm}$ cuvette and absorbance at 446 was measured using spectrophotometer UV2450 (Shimadzu, Japan). Hexane was used as blanco solution. Vitamin A activity of $\beta$-carotene was calculated as suggested by WHO \& FAO (1967), at which 1 IU vitamin $A=0.6 \mu \mathrm{g} \beta$-carotene. Total $\beta$-carotene was calculated using following formula:

$$
\beta \text {-carotene }(\mathrm{ppm})=\frac{25 \times 383 \times \text { sample absorbance }}{100 \times \text { sample weight }(\mathrm{g})}
$$

\section{Vitamin A}

Determination of vitamin A concentration in fortified palm cooking oil using HPLC referred to Tanumihardjo \& Penniston (2002) methodwith a modification.

\section{Standard Curve}

As much as $200 \mu \mathrm{L}$ of a mixture of $\mathrm{KOH}: \mathrm{H} 2 \mathrm{O}\left(50: 50, \mathrm{w} \mathrm{v}^{-1}\right)$ was added to 40 $\mu \mathrm{L}$ of retinyl acetate standard. The mixture was incubated in water bath at $45^{\circ} \mathrm{C}$ for 20 minutes. As much as $200 \mu \mathrm{L}$ water was added to the mixture. Standard mixture was extracted with $1 \mathrm{~mL}$ hexane, it was then vortex and centrifuged. The top layer was put to a new tube; repeat the extraction process with hexane. The top layer obtained was then evaporated under nitrogen. The standard solution was dissolved with $100 \mu \mathrm{L}$ of a mixture of methanol:ethylene dichloride (50:50). As much as $25 \mu \mathrm{L}$ of standard solution was injected to HPLC with flow rate of $1.2 \mathrm{~mL}$ $\mathrm{min}^{-1}$ (mobile phase of methanol:water $\left(89: 11 \mathrm{v} \mathrm{v}^{-1}\right)$, wavelength at $325 \mathrm{~nm}$, run time $15 \mathrm{~min})$.

\section{Sample Preparation}

As much as $25 \mu \mathrm{L}$ of oil sample was put in a tube; respectively $100 \mu \mathrm{L}$ of internal standard (retinyl acetate), $750 \mu \mathrm{L}$ of ethanol and $400 \mu \mathrm{L}$ of a mixture of $\mathrm{KOH}: \mathrm{H} 2 \mathrm{O}$ (50:50, $\left.\mathrm{w} \mathrm{V}^{-1}\right)$ were added to the sample. The mixture was incubated in water bath at $45^{\circ} \mathrm{C}$ for 1 hour. The mixture was extracted 3 times with $0.5 \mathrm{~mL}$ of hexane; and it was then evaporated under nitrogen. The sample was dissolved in $100 \mu \mathrm{L}$ methanol:dichloromethane $(75: 25)$ mixture. As much as $25 \mu \mathrm{L}$ of sample was injected to HPLC with flow rate of $1.0 \mathrm{~mL} \mathrm{~min}^{-1}$ (mobile phase of methanol:water $\left(89: 11 \mathrm{v} \mathrm{v}^{-1}\right)$, wavelength at $335 \mathrm{~nm}$, run time $10 \mathrm{~min}$ ). Vitamin A content in cooking oil was calculated using linear regression equation $(Y=a+b X)$ obtained from standard curve.

\section{Calculation of Vitamin A Concentration}

Vitamin A concentration was calculated using linear regression equation $(Y=a+b X)$ obtained from the standard curve, with $Y$ was the area, and $X$ was vitamin $A$ concentration (in $\mu \mathrm{g} \mathrm{mL^{-1 }}$ retinol). Vitamin $A$ concentration in $\mu \mathrm{g} \mathrm{mL}^{-1}$ retinol was then converted into $\mathrm{IU} \mathrm{g}^{-1}$.

\section{Data Analysis}

All data were input into a Microsoft Excel 2007 spreadsheet. Averages and 
standard deviations were carried out on the data. A scatter plot to investigate the relationship between peroxide formation and vitamin $A$ degradation (total retinyl palmitate and $\beta$-carotene) in the fortified oil samples during storage was made using simple first order reaction model. Simple zero order equation (4) was used for modeling the kinetics of the peroxide formation and vitamin A activity degradation in fortified palm cooking oils during storage at different temperatures.

$$
\frac{d[X]}{d t}=k
$$

where $(d[X] / d t)$ is a reaction rate (increase of peroxide value or decrease of vitamin $A$ activity) and $k$ is the reaction rate constant (in unit of concentration/time). Activation energy (Ea) of oxidation reaction in palm cooking oil during storage was used to predict the oil shelf life in the dark at room temperature $\left(30^{\circ} \mathrm{C}\right)$. Following is the Arrhenius equation (5) to determine activation energy value:

$$
\ln k=\ln A-(E a / R T)
$$

where $k$ is reaction rate constant; $A$ is frequency factor; $R$ is the gas constant (8.314 J/K mol); and $T$ is a temperature (in units of degree of Kelvin). A plot of In $\mathrm{k}$ vs $1 / \mathrm{T}$ gives a straight line and its slope can be used to determine Ea.

\section{RESULTS \& DISCUSSION}

Theinitial chemical characteristics of twelve fortified palm cooking oils, retinyl palmitate and red palm oil used in this study are shown on Table 1. The information of fortificants characteristics is useful to calculate the amount of bulk palm cooking oil and fortificant(s) should be added for the fortification to obtain the vitamin A in the fortified oil at least $45 \mathrm{IU} \mathrm{g}^{-1}$. Of Table 1, it can be seen that the oxidative level of the fortified oil samples were different.
The oxidation level of vegetable oil is an important quality criterion before it is fortified (Pignitter et al. 2016). Peroxide value (PV) and free fatty acid (FFA) concentration are two oxidation products which are commonly used to measure the oxidative deterioration in the oil (Frega et al. 1999). Recent studies from Indonesia and Egypt reported that $\mathrm{PV}$ in the vegetable oil was the important indicator that should be concerned prior to fortification (Laillou et al. 2012). The peroxide value and retinyl palmitate concentration in the fortified palm cooking oil gradually increased and degraded respectively along with the length of storage (Andarwulan et al. 2014). Cooking oil with high PV notably affected the stability of retinyl palmitate added to the oil (Silalahi et al. 2017). Our present study revealed that palm cooking oil with high PV caused vitamin A oxidizes and loses its activity faster than that with lower PV (Figure 1). As expected, the formation of free fatty acid in palm cooking oil increased during the length of storage but it did not change significantly (data not shown). This result was similar to the study conducted by Andarwulan et al. (2014). Therefore, the relationship between the formation of free fatty acid and vitamin A degradation in the fortified palm cooking oils was not further investigated in this present study.

\section{Kinetics of Peroxide Formation in Fortified Palm Cooking Oils}

Kinetic data are essential for predicting oxidative stability of vegetable oils under various heat processing, storage and distribution conditions (Tan et al. 2001). As previously mentioned, all twelve fortified palm cooking oil (FO) samples stored in the dark at elevated temperatures underwent lipid oxidation reaction indicated by the significant increase of peroxide value (PV) during the length of storage. The 
Table 1 The initial chemical characteristics of twelve fortified palm cooking oils. retinyl palmitate and red palm oil used in this study

\begin{tabular}{|c|c|c|c|c|}
\hline Type of oil & $\begin{array}{l}\text { Peroxide value } \\
\qquad\left(\mathrm{mEq} \mathrm{kg}^{-1}\right)\end{array}$ & $\begin{array}{l}\text { Free fatty acid } \\
(\%)\end{array}$ & $\begin{array}{c}\text { B-karoten } \\
\left(\mathrm{IU} \mathrm{g}^{-1}\right)\end{array}$ & $\begin{array}{c}\text { Retinyl palmitate } \\
\left(\mathrm{IU} \mathrm{g}^{-1}\right)\end{array}$ \\
\hline Red palm oil & 0.000 & 0.138 & 728.333 & 0.000 \\
\hline Retinyl palmitate & 0.000 & 0.097 & 0.000 & 789.894 \\
\hline \multicolumn{5}{|c|}{ Fortified oil A (FOA) } \\
\hline Pvi \pm 0 (FOA0) & 0.000 & 0.090 & 0.000 & 55.850 \\
\hline Pvi \pm 4 (FOA4) & 3.995 & 0.238 & 0.000 & 51.360 \\
\hline Pvi \pm 8 (FOA8) & 8.987 & 0.254 & 0.000 & 67.490 \\
\hline \multicolumn{5}{|c|}{ Fortified oil B (FOB) } \\
\hline Pvi \pm 0 (FOB0) & 0.000 & 0.097 & 16.560 & 33.590 \\
\hline Pvi \pm 4 (FOB4) & 3.938 & 0.165 & 16.232 & 37.190 \\
\hline Pvi \pm 8 (FOB8) & 7.950 & 0.213 & 17.547 & 32.590 \\
\hline \multicolumn{5}{|c|}{ Fortified oil C (FOC) } \\
\hline Pvi \pm 0 (FOC0) & 0.000 & 0.097 & 31.749 & 20.090 \\
\hline Pvi \pm 4 (FOC4) & 3.974 & 0.167 & 31.841 & 20.170 \\
\hline Pvi \pm 8 (FOC8) & 7.963 & 0.181 & 33.219 & 18.250 \\
\hline \multicolumn{5}{|c|}{ Fortified oil A (FOD) } \\
\hline Pvi \pm 0 (FOD0) & 1.990 & 0.090 & 45.183 & 0.000 \\
\hline Pvi \pm 4 (FOD4) & 4.000 & 0.240 & 46.083 & 0.000 \\
\hline Pvi \pm 8 (FOD8) & 9.990 & 0.250 & 46.067 & 0.000 \\
\hline SNI 7709: 2019 & $\left.\operatorname{Max} 10^{\star}\right)$ & $\operatorname{Max} 0.3$ & $\left.\operatorname{Min} 45^{\star}\right)$ & \\
\hline
\end{tabular}

Note: Fortified Oil A (FOA): 45 IU retinyl palmitate+0 IU $\beta$-karoten; Fortified Oil B (FOB): 30 IU retinyl palmitate+15 IU $\beta$-karoten; Fortified Oil C (FOC): 15 IU retinyl palmitate+30 IU $\beta$-karoten; Fortified Oil D (FOD): 0 IU retinyl palmitate+45 IU $\beta$-karoten; Pvi: Peroxide value initial $\left.\left(\mathrm{mEq} \mathrm{kg}{ }^{-1}\right){ }^{*}{ }^{*}\right)$ take samples at the factory.

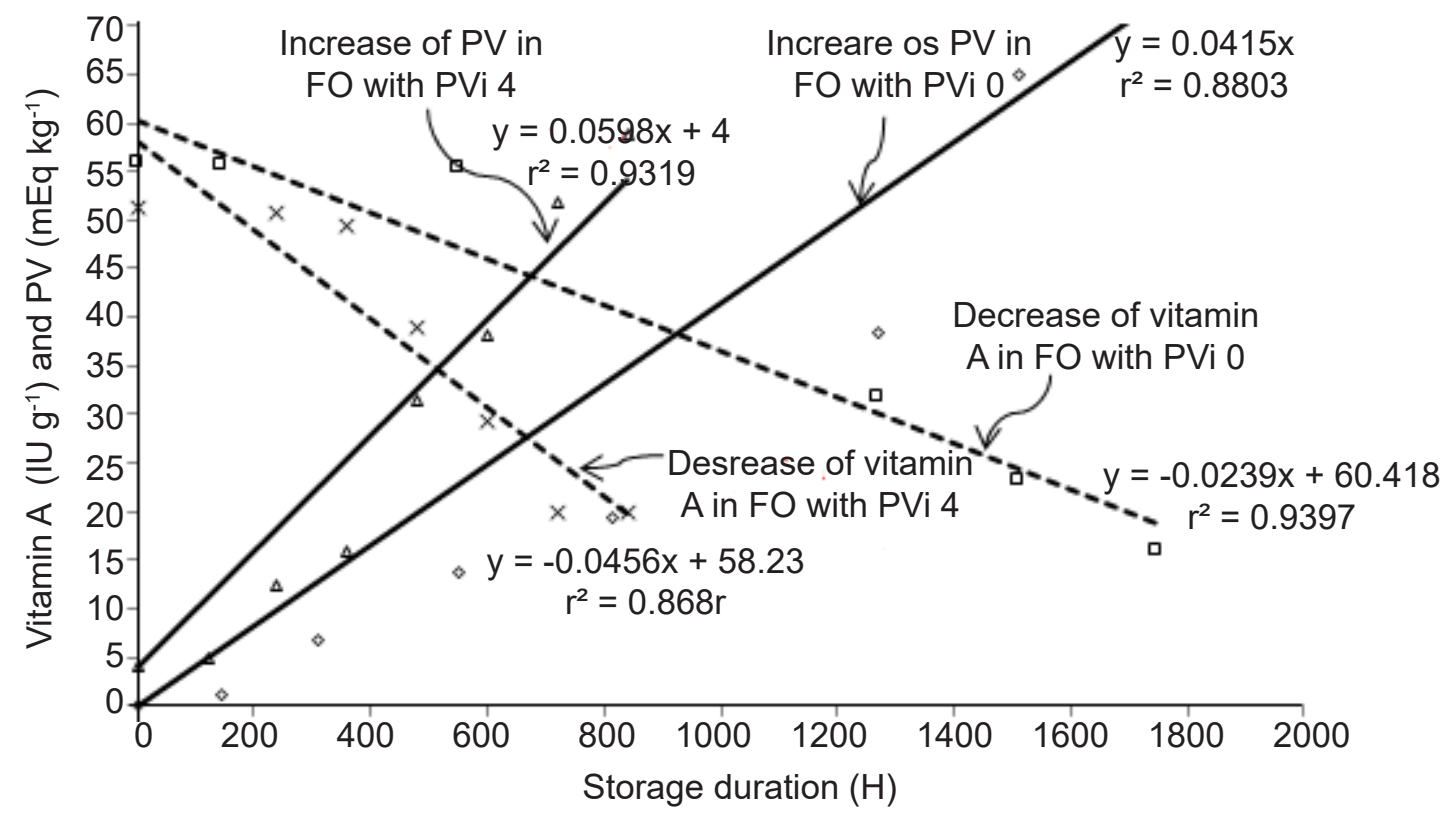

Figure 1 Increase of peroxide value (PV) and degradation of vitamin A activity in fortified palm cooking oils (FO) with a high and low initial PV when stored at $60 \pm 5^{\circ} \mathrm{C}$. 
higher the storage temperature and the initial PV in fortified palm cooking oil, the faster the reaction of peroxide formation indicated by higher reaction rate constant ( $k$ values) of the fortified palm cooking oil during storage. An interesting result revealed that the addition of fortificant mixtures to the palm cooking oil did affect the peroxide formation reaction (Figure 2). The $k$ values for peroxide formation of palm cooking oils with a $\mathrm{PV}$ of $\pm 0 \mathrm{mEq} \mathrm{O}_{2}$ $\mathrm{kg}^{-1}$ fortified with mixtures of retinyl palmitate and RPO- $\beta$-carotene simultaneously, i.e. $\mathrm{FOB}_{0}$ and $\mathrm{FOC}_{0}$ and stored at 60 ${ }^{\circ} \mathrm{C}$ were 0.061 and $0.089 \mathrm{mEq} \mathrm{O}_{2} \mathrm{~kg}^{-1} \mathrm{~h}^{-1}$ respectively. These $k$ values for peroxide formation were higher than that of palm cooking oils fortified with retinyl palmitate or RPO- $\beta$-carotene alone $\left(\mathrm{k}_{\mathrm{FOA} 0}=0.043\right.$ $\mathrm{mEq} \mathrm{O} 2 \mathrm{~kg}^{-1} \mathrm{~h}^{-1}$ and $\mathrm{k}_{\mathrm{FODO}}=0.041 \mathrm{mEq} \mathrm{O}_{2}$ $\left.\mathrm{kg}^{-1} \mathrm{~h}^{-1}\right)$. This phenomenon occurred almost in all other fortified palm cooking oils with different initial PVs and when they were stored at other storage temperatures (Table 2).

Retinyl palmitate and RPO- $\beta$-carotene itself may have potential as antioxidant to maintain the oil quality during storage (Pignitter et al. 2014). Both can act as a chain-breaking antioxidant or lipid radical scavenger by trapping free radicals to stop the chain reaction and as a singlet oxygen quencher due to a series of conjugated double bonds system which can impart prooxidant character to the molecule (Choe \& Min 2009). The fact that RPO contained the high amount of $\beta$-carotene (over 500 ppm) as well as high vitamin E, RPO is considered as a good source of natural antioxidant oil (Dauqan et al. 2011). However, our data shows that addition of retinyl palmitate and RPO- $\beta$-carotene simultaneously in palm cooking oil made the oil was more prone to oxidation than that of oil fortified with a single fortificant, either retinyl palmitate or RPO- $\beta$-carotene. This finding suggests that retinyl palmitate and RPO- $\beta$-carotene might act antagonistically as antioxidants, resulting in more rapid oxidative damage of palm cooking oil. Detail mechanism of the interaction between retinyl palmitate and RPO- $\beta$-carotene, however, is unknown.

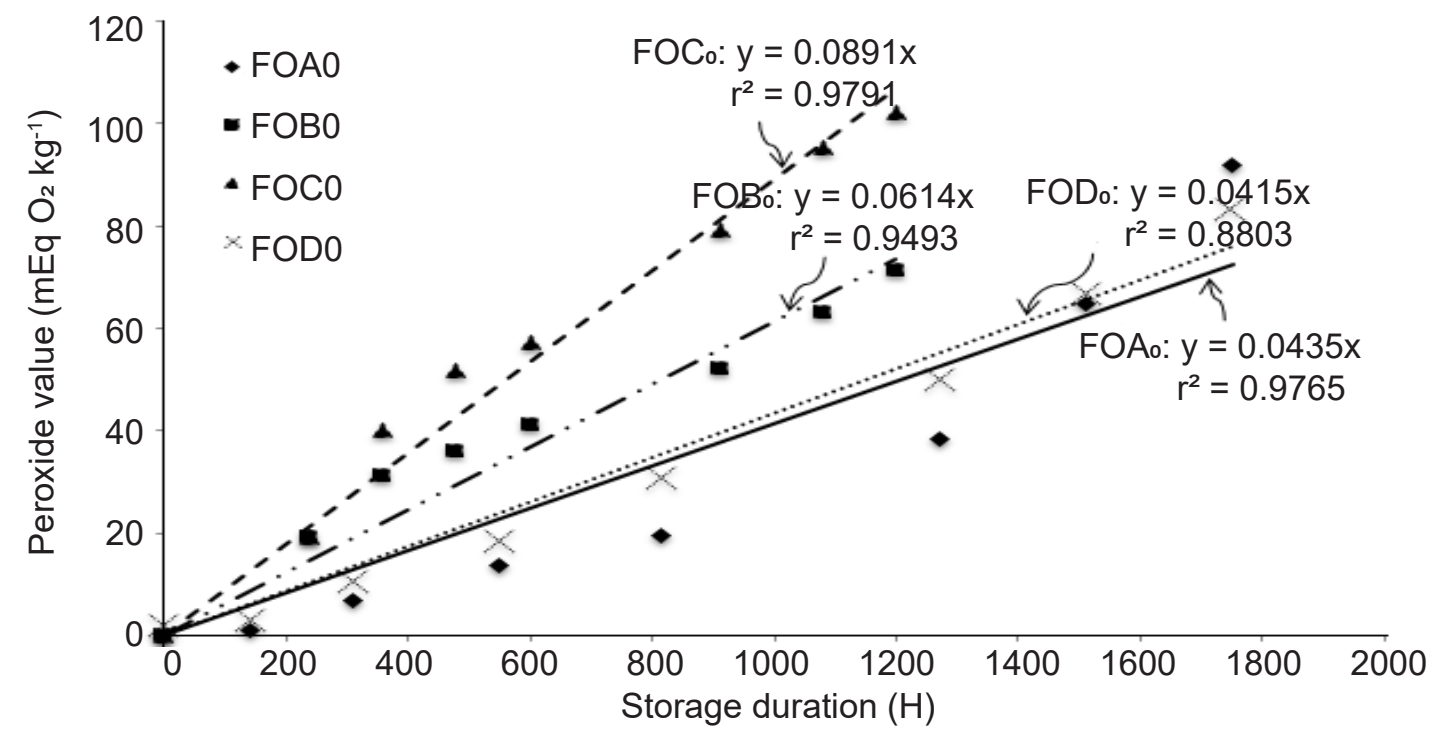

Figure 2 Zero order kinetics model of peroxide formation in fortified palm cooking oils with a PV of \pm 0 $\mathrm{mEq} \mathrm{O} \mathrm{kg}^{-1}$ stored at $60 \pm 5^{\circ} \mathrm{C}$. 
Table 2 The $k$ values for peroxide formation of palm cooking oils

\begin{tabular}{|c|c|c|c|c|c|c|c|}
\hline \multirow{3}{*}{ Oil samples } & \multirow{3}{*}{ Pvi } & \multicolumn{6}{|c|}{ Temperature storage $\left({ }^{\circ} \mathrm{C}\right)$} \\
\hline & & \multicolumn{2}{|c|}{$60 \pm 5$} & \multicolumn{2}{|c|}{$75 \pm 5$} & \multicolumn{2}{|c|}{$90 \pm 5$} \\
\hline & & k & $\mathrm{R}^{2}$ & k & $\mathrm{R}^{2}$ & $\mathrm{~K}$ & $\mathrm{R}^{2}$ \\
\hline FOA & \multirow{4}{*}{ \pm 0} & 0.042 & 0.880 & 0.162 & 0.958 & 0.297 & 0.990 \\
\hline FOB & & 0.061 & 0.949 & 0.234 & 0.969 & 0.315 & 0.916 \\
\hline FOC & & 0.089 & 0.979 & 0.198 & 0.973 & 0.303 & 0.965 \\
\hline FOD & & 0.042 & 0.968 & 0.114 & 0.911 & 0.255 & 0.989 \\
\hline FOA & \multirow{4}{*}{ \pm 4} & 0.060 & 0.932 & 0.185 & 0.979 & 0.247 & 0.993 \\
\hline FOB & & 0.086 & 0.947 & 0.244 & 0.993 & 0.305 & 0.935 \\
\hline FOC & & 0.100 & 0.964 & 0.230 & 0.947 & 0.314 & 0.934 \\
\hline FOD & & 0.055 & 0.980 & 0.211 & 0.995 & 0.412 & 0.990 \\
\hline FOA & \multirow{4}{*}{ \pm 8} & 0.062 & 0.961 & 0.215 & 0.970 & 0.230 & 0.974 \\
\hline FOB & & 0.111 & 0.968 & 0.243 & 0.964 & 0.297 & 0.968 \\
\hline FOC & & 0.138 & 0.971 & 0.259 & 0.979 & 0.302 & 0.970 \\
\hline FOD & & 0.054 & 0.985 & 0.283 & 0.954 & 0.484 & 0.998 \\
\hline
\end{tabular}

Note: Fortified Oil A (FOA): 45 IU retinyl palmitate+0 IU $\beta$-karoten; Fortified Oil B (FOB): 30 IU retinyl palmitate +15 IU $\beta$-karoten; Fortified Oil C (FOC): 15 IU retinyl palmitate+30 IU $\beta$-karoten; Fortified Oil D (FOD): 0 IU retinyl palmitate+45 IU $\beta$-karoten; Pvi: Peroxide value initial $\left.\left(\mathrm{mEq} \mathrm{kg}^{-1}\right) ;{ }^{*}\right)$ take samples at the factor.

Table 2 shows that the activation energy (Ea) of peroxide formation in palm cooking oil fortified with mixture of retinyl palmitate and RPO- $\beta$-carotene simultaneously (FOB and FOC) were always lower than that fortified with retinyl palmitate and RPO- $\beta$-carotene alone (FOA and FOD) at the same PV. This finding suggests that in addition to the higher reaction rate of peroxide formation in FOB and FOC (indicated by higher value of $k$, Table 2), the reaction rate of peroxide formation in $\mathrm{FOB}$ and FOC are less sensitive to temperature changes. Meaning that reducing temperature of storage would not significantly reduce the rate of lipid oxidation in $\mathrm{FOB}$ and FOC, as compared to that in FOA and FOD. The results also revealed that palm cooking oil fortified with RPO- $\beta$-carotene (FOD) had the opposite pattern compare to other fortified palm cooking oils. The higher $\mathrm{PV}$ in FOD the higher its activation energy which means the reaction rate of peroxide formation in the oil was slower (Table 2). FOD was indeed more prone to oxidation at high temperature $\left(\geq 60^{\circ} \mathrm{C}\right)$ due to its higher reaction rate constant than other fortified cooking oils, but it will be more stable if stored at much lower temperature in the dark (Figure 3).

\section{Kinetics Degradation of Vitamin A Activity in Fortified Palm Cooking Oils}

The reaction rate constant for vitamin A degradation in twelve fortified palm cooking oils is shown on Table 3. Likewise the peroxide formation, the reaction rate constant for vitamin $A$ degradation in FOB and FOD of any initial PVs at $60 \pm 5$ ${ }^{\circ} \mathrm{C}$ and $75 \pm 5{ }^{\circ} \mathrm{C}$ were higher than that of FOA and FOD. Again, these findings confirm that fortifications of palm cooking oil with combination of retinyl palmitate and RPO- $\beta$-carotene simultaneously made them more easily deteriorated. However, at $90 \pm 5{ }^{\circ} \mathrm{C}$ the opposite pattern occurred in which FOA and FOD had higher reaction rate constant than FOB and FOC. The higher the storage temperature and the initial PV in fortified palm cooking oil the faster its degradation rate of vitamin A activity. A mixture of fortificants affected the reaction degradation rate of vitamin $A$ activity in fortified palm cooking oils. The 


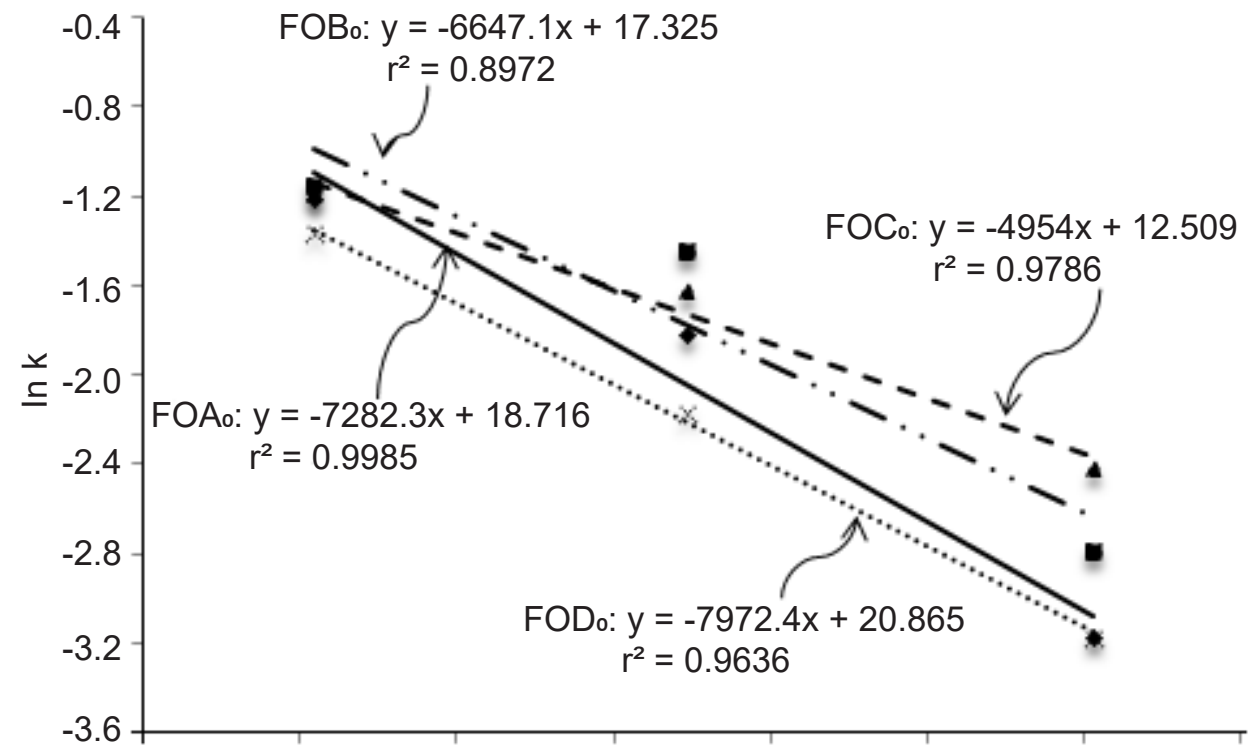

2.70E-03 2.75E-03 2.80E-03 2.85E-03 2.90E-03 2.95E-03 3.00E-03 3.05E-03

$\mathrm{IT} / \mathrm{K}$

- $\mathrm{FOAO} \backsim \mathrm{FOBO} \triangle \mathrm{FOCO} \times \mathrm{FODO}$

Figure 3 Arrhenius plot of formation rate constant of peroxide in fortified palm cooking oils with a PV of $\pm 0 \mathrm{mEq} \mathrm{O}_{2} \mathrm{~kg}^{-1}$.

Table 3 The reaction rate constant for vitamin A degradation in twelve fortified palm cooking oils

\begin{tabular}{|c|c|c|c|c|c|c|c|}
\hline \multirow{3}{*}{ Oil samples } & \multirow{3}{*}{ Pvi } & \multicolumn{6}{|c|}{ Temperature storage $\left({ }^{\circ} \mathrm{C}\right)$} \\
\hline & & \multicolumn{2}{|c|}{$60 \pm 5$} & \multicolumn{2}{|c|}{$75 \pm 5$} & \multicolumn{2}{|c|}{$90 \pm 5$} \\
\hline & & $\mathrm{K}$ & $\mathrm{R}^{2}$ & $\mathrm{~K}$ & $\mathrm{R}^{2}$ & $\mathrm{~K}$ & $\mathrm{R}^{2}$ \\
\hline FOA & \multirow{4}{*}{ \pm 0} & 0.037 & 0.911 & 0.156 & 0.888 & 0.437 & 0.949 \\
\hline FOB & & 0.089 & 0.859 & 0.228 & 0.996 & 0.439 & 0.634 \\
\hline FOC & & 0.090 & 0.911 & 0.196 & 0.937 & 0.399 & 0.888 \\
\hline FOD & & 0.030 & 0.960 & 0.135 & 0.890 & 0.281 & 0.915 \\
\hline FOA & \multirow{4}{*}{ \pm 4} & 0.067 & 0.799 & 0.234 & 0.792 & 0.606 & 0.948 \\
\hline FOB & & 0.098 & 0.814 & 0.289 & 0.833 & 0.422 & 0.986 \\
\hline FOC & & 0.092 & 0.617 & 0.277 & 0.881 & 0.446 & 0.942 \\
\hline FOD & & 0.052 & 0.908 & 0.197 & 0.946 & 0.409 & 0.827 \\
\hline FOA & \multirow{4}{*}{ \pm 8} & 0.143 & 0.836 & 0.234 & 0.792 & 0.561 & 0.947 \\
\hline FOB & & 0.158 & 0.576 & 0.289 & 0.833 & 0.445 & 0.953 \\
\hline FOC & & 0.140 & 0.873 & 0.277 & 0.881 & 0.418 & 0.949 \\
\hline FOD & & 0.129 & 0.977 & 0.197 & 0.946 & 0.507 & 0.841 \\
\hline
\end{tabular}

Note: Fortified Oil A (FOA): 45 IU retinyl palmitate +0 IU $\beta$-karoten; Fortified Oil B (FOB): 30 IU retinyl palmitate +15 IU $\beta$-karoten; Fortified Oil C (FOC): 15 IU retinyl palmitate+30 IU $\beta$-karoten; Fortified Oil D (FOD): 0 IU retinyl palmitate+45 IU $\beta$-karoten; Pvi: Peroxide value initial $\left(\mathrm{mEq} \mathrm{kg}^{-1}\right)$; *) take samples at the factor

FOB and FOC tend to have faster degradation rate of vitamin $A$ activity than that of FOA and FOD during storage at the elevated temperatures. This is associated with higher activation energy in FOB and FOC (Figure 4) as discussed previously.
Our finding suggests that there was no a synergetic antioxidant activity from both retinyl palmitate and RPO- $\beta$-carotene in combination to trapping free radicals and stop the oxidation reaction occurred in the FOB and FOC. Vitamin A activity in 


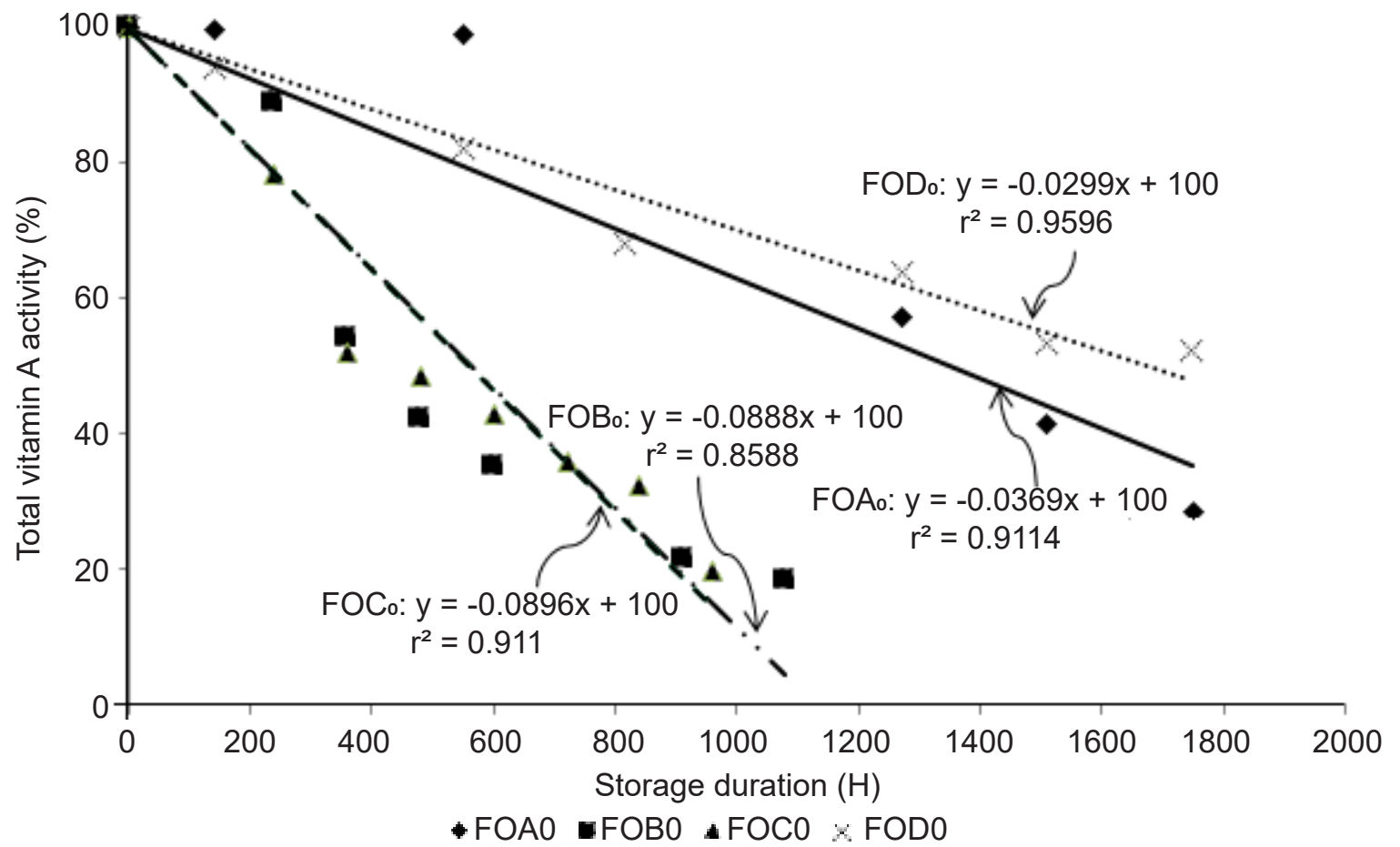

Figure 4 Zero order kinetics model of vitamin A activity degradation in fortified palm cooking oils with a $\mathrm{PV}$ of $\pm 0 \mathrm{mEq} \mathrm{O} \mathrm{kg}^{-1}$ stored at $60 \pm 5^{\circ} \mathrm{C}$.

FOA and FOD were indeed more prone to deteriorate than FOB and FOC at high temperature $\left(\geq 90{ }^{\circ} \mathrm{C}\right)$. It might be due to at high storage temperature compounds like $\beta$-carotene and tocopherol in oils, in this case was red palm oil, showed no cooperative interaction which can inhibit the oxidation reaction rate. $\beta$-carotene acts as pro-oxidant during thermal treatment at higher exposure time and high temperature. However, FOA and FOD will undergo a slower reaction rate of vitamin $A$ degradation if stored at lower temperature in the dark (Figure 5).

\section{CONCLUSION}

Peroxide value is the main quality criterion of cooking oil before fortification. In this study, kinetic analysis of vitamin A degradation in fortified palm cooking oils with low $\mathrm{PV}\left(\mathrm{PVi} \pm 0 \mathrm{mEq} \mathrm{O} \mathrm{kg}^{-1}\right.$ ) shows to have a slower reaction rate of vitamin A degradation than that with a high PV ( $\mathrm{PVi} \pm 4$ and $\pm 8 \mathrm{mEq} \mathrm{O} \mathrm{kg}^{-1}$ ). The stability of palm cooking oil fortified with retinyl palmitate and RPO- $\beta$-carotene alone are more stable than that fortified with retinyl palmitate and RPO- $\beta$-carotene in combination simultaneously. Therefore, it is not recommended to combine these two fortificants simultaneously to fortify cooking oil because they show a synergistic interaction that can increase oxidation reaction rate during storage.

\section{ACKNOWLEDGEMENTS}

We would like to thank Indonesia Nutrition Foundation for Food Fortification (KFI), especially to Mr. Soekirman and his team, for partial financial support for the study. 


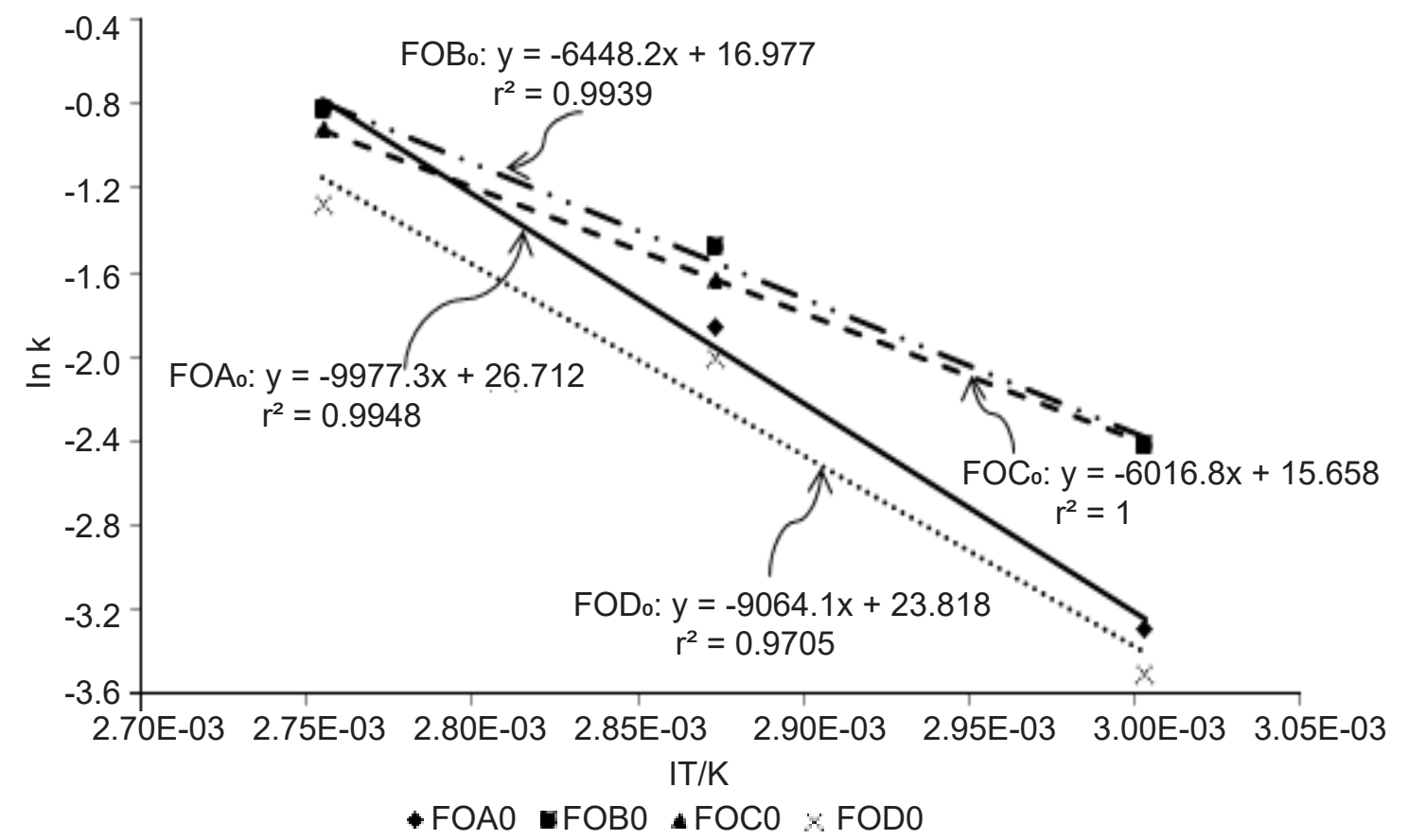

Figure 5 Arrhenius plot of degradation rate constant of vitamin A activity in fortified palm cooking oils with a $\mathrm{PV}$ of $\pm 0 \mathrm{mEq} \mathrm{O} \mathrm{kg}^{-1}$.

\section{REFERENCES}

[AOAC] Association of Official Analytical Chemists. 2000. Official method of analysis. 17th ed. Gaithersburg (US): AOAC.

[AOCS] American Oil Chemists' Society. 1998. Official methods and recommended practices of the AOCS. 5th ed. Urbana (US): AOCS.

Akhtar S, Ahmed A, Randhawa MA, Atukorala S, Arlappa N, Ismail T, Ali Z. 2013. Prevalence of vitamin A deficiency in South Asia: causes, outcomes, and possible remedies. JHPN. 31(4):413-423.

Andarwulan N, Gitapratiwi D, Laillou A, Fitriani D, Hariyadi P, Moench-Pfanner R, Martianto D. 2014. Quality of vegetable oil prior to fortification is an important criteria to achieve a health impact. Nutrients. 6(11):5051-5060. DOI:10.3390/nu6115051.
Benadé AJS. 2003. A place for palm fruit oil to eliminate vitamin A deficiency. Asia Pac J Clin Nutr. 12(3):369-372.

Bruins M, Kraemer K, Hopkins J. 2013. Public health programmes for vitamin A deficiency control. CEHJ. 26(84):6970. DOI:10.1136/bmj.d5094.2.

Chadare FJ, Idohou R, Nago E, Affonfere M, Agossadou J, Fassinou TK, Hounhouigan DJ. 2019. Conventional and food-to-food fortification: an appraisal of past practices and lessons learned. Food Sci Nutr. 7(9):2781-2795. DOI:10.1002/ fsn3.1133.

Choe E, Min DB. 2009. Mechanisms of antioxidants in the oxidation of foods. CRFSFS. 8(4):345-358. DOI:10.1111/ j.1541-4337.2009.00085.x.

Dauqan E, Sani HA, Abdullah A, Muhamad H, Gapor Md Top AB. 2011. Vitamin E and beta carotene composition in four different vegetable oils. Am J Appl Sci. 8(5):407412. DOI:10.3844/ajassp.2011.407.412. 
Frega N, Mozzon M, Lercker G. 1999. Effects of free fatty acids on oxidative stability of vegetable oil. JAOCS. 76(3): 325-329. DOI:10.1007/s11746-9990239-4.

Grune T, Lietz G, Palou A, Ross AC, Stahl W, Tang G, Biesalski HK. 2010. $\beta$-carotene is an important vitamin $A$ source. ASN. 140(12):2268S-2285S. DOI:10.3945/jn.109.119024.

Laillou A, Hafez SA, Mahmoud AH, Mansour M, Rohner F, Fortin S, Moench-Pfanner R. 2012. Vegetable oil of poor quality is limiting the success of fortification with vitamin $A$ in Egypt. Food Nutr Bull. 33(3):186-193. DOI:10.1177/156482651203300303.

Laillou A, Panagides D, Garrett GS, Moench-Pfanner R. 2013. Vitamin A-fortified vegetable oil exported from Malaysia and Indonesia can significantly contribute to vitamin A intake worldwide. Food Nutr Bull. 34(2 Suppl):72-80. DOI:10.1177/15648265130342s109.

Pignitter M, Dumhart B, Gartner S, Jirsa F, Steiger G, Kraemer K, Somoza V. 2014. Vitamin $A$ is rapidly degraded in retinyl palmitate-fortified soybean oil stored under household conditions. J Agr Food Chem. 62(30):7559-7566. DOI:10.1021/j5502109j.

Pignitter M, Hernler N, Zaunschirm M, Kienesberger J, Somoza MM, Kraemer K, Somoza V. 2016. Evaluation of palm oil as a suitable vegetable oil for vitamin A fortification programs. Nutrients. 8(6):1-13. DOI:10.3390/nu8060378.

Silalahi DKN, Yuliyanti $D$, da Silva $M$, Christianti I, Mulyono K, Wassell P. 2017. The stability of vitamin A in fortified palm olein during extended storage and thermal treatment. Int J Food Sci Tech. 52(8):1869-1877. DOI:10.1111/ ijfs.13462.

Simonne AH, Eitenmiller RR. 1998. Retention of vitamin $E$ and added retinyl palmitate in selected vegetable oils during deep-fat frying and in fried breaded products. J Agr Food Chem. 46(12):5273-5277. DOI:10.1021/ jf9802528.

Souganidis E, Laillou A, Leyvraz M, Moench-pfanner R. 2013. A comparison of retinyl palmitate and red palm oil $\beta$-carotene as strategies to address vitamin A deficiency. Nutrients. 5(8):3257-3271. DOI:10.3390/ nu5083257.

Tan CP, Che Man YB, Selamat J, Yusoff MSA. 2001. Application of Arrhenius kinetics to evaluate oxidative stability in vegetable oils by isothermal differential scanning calorimetry. JAOCS. 78(11): 1133-1138. DOI:10.1007/s11746-0010401-1.

[WHO \& FAO] World Health Organization and Food Agricultural Organinzation of the United Nations. 1967. Requirements of vitamin $\mathrm{A}$, thiamine, riboflavine and niacin. Technical report series No. 362. FAO nutrition meetings report series No. 41. Geneva $(\mathrm{CH})$ : WHO.

[WHO \& FAO] World Health Organization and Food Agricultural Organinzation of the United Nations. 2006. Evaluating the public health significance of micronutrient malnutrition. In: Lindsay A, de Benoist B, Dary O, Hurrell R, editors. Guidelines on food fortification with micronutrients. Geneva $(\mathrm{CH})$ : WHO. p.43-54. 